\title{
The effects of a hospital smoking ban on employee smoking behaviour and participation in different types of smoking cessation programmes
}

\author{
H Richard Waranch, William K Wohlgemuth, Donald A Hantula, Ricardo Gorayeb,
} Frances A Stillman

\begin{abstract}
Objective-To evaluate the effects of a smoking ban at Johns Hopkins Hospital on employee smoking behaviour and participation in a variety of stop-smoking programmes.

Design - A prospective descriptive study of 262 employees who participated in a variety of stop-smoking programmes. The employees were contacted one year after implementation of a smoking ban to determine smoking status, and a survey of hospital employees was conducted six months before and six months after the ban.
\end{abstract}

Setting - The Johns Hopkins Hospital, a privately owned hospital in Baltimore, Maryland, USA, with almost $9000 \mathrm{em}-$ ployees.

Subjects - A total of 5190 employees who responded to an initial survey about smoking behaviour and 262 employees who participated in hospital-sponsored stop-smoking programmes.

Results - Of the estimated 2000 smokers working in the hospital $13.1 \%$ (262) chose to participate in hospital-sponsored smoking cessation programmes prior to implementation of the smoking ban. One year after the ban, $8.4 \%$ (22) were not smoking. Six months following the ban, the self-reported prevalence of smoking among all employees decreased from $21.7 \%$ to $16.2 \%$ and the number of cigarettes smoked decreased significantly for employees in all occupational categories. Group attendance at a multicomponent group programme quadrupled during the 12-month period following the announcement of the impending ban and returned to near pre-ban levels in the subsequent 12-month period.

Conclusion-Although participation in hospital-sponsored stop-smoking programmes increased substantially in the year following the announcement of a smoking ban, participants only represented a small percentage of the employees who smoked. Most employees reported reducing their daily cigarette consumption following the smoking ban but relatively few employees stopped smoking.

(Tobacco Control 1993; 2: 120-126)
Introduction

The proliferation of policies restricting and banning smoking in the workplace is considered to be one of the most effective means of reducing smoking prevalence in the future. ${ }^{1}$ The 1991 Bureau of National Affairs' survey of worksite smoking policies indicated that $85 \%$ of responding firms had smoking policies designed to address employee health and comfort and $34 \%$ had total bans on smoking. ${ }^{2}$ Legislation restricts smoking in public workplaces in 41 states and private workplaces in 18 states, while 34 states have legislated smoking restrictions within hospitals. ${ }^{3}$ A survey in 1988 of 774 university-affiliated medical institutions reported that $90 \%$ had implemented some type of restrictions on smoking and a 1990 survey of all accredited schools of medicine in the US indicated that $80.5 \%$ had some type of smoking policy. ${ }^{4,5}$

Restrictive worksite smoking policies seem to have emerged because of two interrelated forces: increasing evidence of the health risks of passive smoking and changing public attitudes about the social acceptability of smoking. ${ }^{6}$ The workplace is the principle site of exposure to environmental tobacco smoke (ETS) for adults who do not live with smokers ${ }^{7}$ and a number of studies show that the majority of adults, both smokers and non-smokers, favour restricting smoking in the workplace. ${ }^{8-11}$

The proportion of adult men and women who smoke has decreased significantly in the past 20 years and $77-86 \%$ of smokers indicate a desire to stop smoking. ${ }^{12}$ A review of smoking cessation studies showed that abstinence rates of formal smoking cessation programmes at 6and 12-month follow-ups clustered around $20 \%$ of those beginning treatment, with only a few programmes showing long-term abstinence rates of $30 \%$ or greater. ${ }^{13}$ For smokers trying to stop completely on their own or with the aid of a self-help manual, cessation rates are typically under $5 \%{ }^{14}$

In a review of trends in the adoption of smoking restrictions in public places and worksites, Rigotti suggested that restricting smoking at work might enhance participation in and effectiveness of smoking cessation programmes and increase the success of smokers' efforts to stop. ${ }^{6}$ By reducing opportunities for smoking, worksite restrictions may also reduce the cigarette consumption of smokers who do not stop. ${ }^{6}$ 
The evidence for the effects of restrictive worksite smoking policies on employee smoking is mixed. The majority of published reports indicate that implementing more restrictive smoking policies at worksites results in only minimal reductions in employee smoking prevalence, ${ }^{11,15-17}$ with only two studies reporting much larger reductions. ${ }^{18,19}$ In contrast, all of these studies report a significant reduction in employee cigarette consumption and low attendance at formal stop-smoking programmes. These studies rely almost exclusively on survey data for their information and provide only very brief descriptions of the smoking cessation programmes and the employees who participated in them.

Previously, we reported on the effects of a policy to eliminate smoking in the Children's Center at Johns Hopkins Hospital ${ }^{20,21}$ in Baltimore, Maryland, USA, and then in the entire Hospital. ${ }^{22}$ In those studies, we described the background and implementation of the smoking bans, the attitudes of employees towards the bans, and the changes in environmental fires, smoking-related litter, pollution from ETS, and overall changes in employee smoking behaviour. In the present study, we focus on the influence of the smoking ban on the participation of employees in different types of worksite-sponsored stopsmoking programmes and on employee smoking behaviour.

\section{Methods}

\section{BACKGROUND}

Following a decision by the Board of Directors of the Johns Hopkins Hospital to eliminate smoking in all areas of the hospital, a steering committee composed of representatives from all major departments was formed to implement the smoke-free policy. The policy was officially announced six months prior to implementation and was followed by an extensive internal communication and educational campaign emphasising the health effects of passive smoking and the benefits of stopping smoking. Free health screening for exhaled carbon monoxide (CO), cholesterol, and blood pressure was offered to all employees beginning six months pre-ban and continuing for one year post-ban. A more detailed description of the entire smoke-free campaign and the outcome has been presented elsewhere. ${ }^{20-22}$

\section{SMOKING CESSATION PROGRAMMES AND} MATERIALS

The smoking cessation materials and programmes described below were offered freeof-charge to all medical institution employees. Announcements describing the availability of these programmes and materials were frequently printed in three different in-house publications. The multicomponent group was the only programme in which non-hospital employees were allowed to participate because these groups had been open to the public for several years.

Multicomponent Group $(n=88 ;$ females $=75$; males $=13$ )

An eight-session group programme was run nine times, with group sizes ranging from 11 to 17 participants. Included in these groups were 34 non-hospital employees who paid for the programme and were not followed-up. The first six sessions were held on consecutive weeks, with the fourth session designated as the target "quit date." The seventh and eighth sessions were held at two-week intervals. The groups were staffed by psychology fellows in behavioural medicine and by preventive medicine resident physicians. Treatment components included measurement of expired alveolar $\mathrm{CO}$, self-monitoring, brand-switching and cutting down, the use of nicotine gum, relaxation techniques, weight control techniques, and coping strategies to prevent relapse. This programme has previously been described in detail. ${ }^{23}$

American Lung Association manual ( $n=59$; females $=50 ;$ males $=9$ ) and LifeSign $(n=59 ;$ females $=47 ;$ males $=12)$

Self-identified smokers who attended a series of employee health fairs where $\mathrm{CO}$ was measured were invited to participate in a study comparing self-help strategies for smoking cessation. These people were seen individually for 15 minutes. CO was measured again and a smoking history form completed. Participants were then randomly given either Freedom from smoking for you and your family (American Lung Association manual) or LifeSign (Health Innovations Inc, Reston, Virginia), a fully dedicated portable computer designed to support attempts to stop smoking.

One-hour clinics $(n=23$; females $=19$; males $=4$ )

Three one-hour clinics were held in the hospital. Employees came in response to announcements in institution publications. Participants had CO levels taken, completed a brief smoking history questionnaire, and were given handouts on passive smoking and $\mathrm{CO}$ plus the Roswell Park Memorial Institute's Smoker's Quit Kit. Participants had the opportunity to ask questions and were given tips on how to stop smoking.

Brief Individual Counselling ( $n=33$;

females $=26 ;$ males $=7$ )

Employees who called asking for help in stopping smoking were seen individually for 15 minutes. Expired $\mathrm{CO}$ was measured and explained and a smoking history form completed. Participants were then given the Roswell Park Memorial Institute's Smoker's Quit Kit.

Each of the above programmes had a higher percentage of females than males (total $=84 \%$ vs. $16 \%$ ). The proportion of females to males across groups was not statistically different. 
The mean age of all participants was 40 years with a range of $20-70$ years. There was no statistically significant difference in age between groups.

\section{FOLLOW-UP}

One year after the hospital became smoke-free, participants were called for a brief telephone interview. They were asked about their current smoking status and the influence of the hospital's no-smoking policy on their decision to try to stop smoking. Those participants who said they were not smoking were encouraged to come in to have their $\mathrm{CO}$ measured.

\section{CO measurements}

Expired alveolar $\mathrm{CO}$ levels were collected by asking participants to hold their breath for 30 seconds and blow into a MiniCO (Catalyst Research Co, Owings Mills, MD) which involves inflating a balloon attached to a sensor. Peak expired CO in ppm is available in 30 seconds. The MiniCO was calibrated according to the manufacturer's directions before each day's use. $\mathrm{CO}$ is a by-product of cigarette smoking which is absorbed into the lungs and provides a reliable indicator of whether a person has been smoking in the previous 24 hours. ${ }^{24}$ Expired CO levels below $10 \mathrm{ppm}$ were considered to be a validation of non-smoking status.

\section{Fagerström scale}

The Fagerström scale, ${ }^{25}$ measuring degree of physical dependence on tobacco, was given to participants in all programmes except (because of an oversight) those in the Brief Individual Counselling groups.

\section{SURVEY}

An initial survey was distributed six months prior to the ban to all full-time permanent employees ( $n=8742$ ) who worked within the hospital complex. Questionnaires, with unique identification numbers and an attached letter from senior medical institution administrators assuring confidentiality, were distributed with employee paychecks and returned by interdepartmental mail. The return rate for the initial survey was $69.2 \%(6050 / 8742)$ but only

Table 1 Number of participants using different smoking cessation methods, number of staff hours required to run each programme, and number of successful quitters

\begin{tabular}{|c|c|c|c|c|c|}
\hline \multirow{2}{*}{$\begin{array}{l}\text { Smoking cessation } \\
\text { method }\end{array}$} & \multirow{2}{*}{$\begin{array}{l}\text { Participants } \\
(n)\end{array}$} & \multirow{2}{*}{$\begin{array}{l}\text { Staff hours to } \\
\text { run programme }\end{array}$} & \multirow{2}{*}{$\begin{array}{l}\text { Participants } \\
\text { followed at } \\
1 \text { year }(n)\end{array}$} & \multicolumn{2}{|c|}{ Successful quitters } \\
\hline & & & & $(n)$ & $(\%)$ \\
\hline $\begin{array}{l}\text { Multicomponent } \\
\text { groups }\end{array}$ & 88 & 72 & 65 & 11 & 12.5 \\
\hline $\begin{array}{l}\text { American Lung } \\
\text { Association manual }\end{array}$ & 59 & 15 & 33 & 2 & 3.4 \\
\hline $\begin{array}{l}\text { LifeSign } \\
\text { One-hour clinics }\end{array}$ & $\begin{array}{l}59 \\
23\end{array}$ & $\begin{array}{r}15 \\
3\end{array}$ & $\begin{array}{l}34 \\
22\end{array}$ & $\begin{array}{l}1 \\
5\end{array}$ & $\begin{array}{r}1.7 \\
21.7\end{array}$ \\
\hline $\begin{array}{l}\text { Brief Individual } \\
\text { Counselling }\end{array}$ & 33 & 11 & 32 & 3 & 9.1 \\
\hline Total & 262 & 116 & 186 & 22 & 8.4 \\
\hline
\end{tabular}

$86 \%$ (5190) were usable based on study criteria of having a valid identification number and completed responses to smoking status questions. Of the 5190 employees who completed and returned a usable questionnaire, 4480 were still employed at the hospital one year later (six months post-ban) and were mailed a similar follow-up questionnaire.

\section{Results}

SMOKING CESSATION PROGRAMMES

Table 1 shows the number of employees who selected each of the different smoking cessation methods, the number of staff hours required to run each programme, and the number of successful quitters from each group. A total of 262 employees participated in the various programmes with the majority participating in self/minimal-help treatments $(66.4 \%)$. Of the 186 participants $(71 \%)$ successfully contacted for a one-year follow-up, 26 reported that they had not smoked for an entire year; CO verification of non-smoking status was obtained for 22 of these, indicating a one-year cessation rate of $8.4 \%$. The total number of staff hours required for the different programmes ranged from three hours for the three one-hour clinics to 72 hours for the nine multicomponent groups.

The figure shows the number of participants, both Johns Hopkins Medical Institution employees and others, in the multicomponent group smoking cessation programme from 1985 to 1989. Prior to the announcement of the impending non-smoking policy, employee participation in the group programme ranged from 22 to 28 per year and appeared quite stable. Participation nearly quadrupled during the 12-month period following announcement of the impending smoking ban and returned to near pre-ban levels in the 12-month period after the ban was implemented.

Table 2 shows the smoking characteristics of participants in each group at baseline and the number of cigarettes smoked at follow-up.

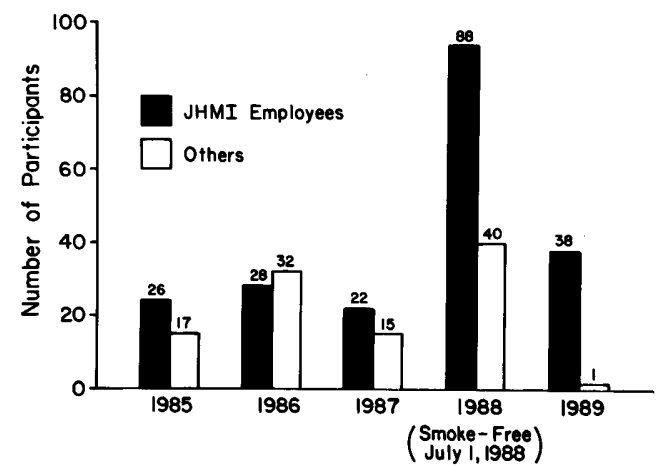

The number of participants who attended $a$. multicomponent group smoking cessation programme between 1985 and 1989. The smoke-free policy was implemented on 1 fuly 1988, following a series of announcements beginning on 1 fanuary 1988. The numbers above the bars indicate the number of participants in each group. 
Table 2 Smoking characteristics of participants at baseline and follow-up

\begin{tabular}{|c|c|c|c|c|c|}
\hline \multicolumn{5}{|c|}{ Baseline } & \multirow{2}{*}{$\begin{array}{c}\text { Follow-up } \\
\begin{array}{c}\text { Mean number } \\
\text { of cigarettes } \\
\text { smoked }\end{array}\end{array}$} \\
\hline $\begin{array}{l}\text { Smoking } \\
\text { cessation } \\
\text { method }\end{array}$ & $\begin{array}{l}\text { Mean number } \\
\text { of cigarettes } \\
\text { smoked }\end{array}$ & $\begin{array}{l}\text { Mean number } \\
\text { of quit } \\
\text { attempts }\end{array}$ & $\begin{array}{l}\text { Mean } \\
\text { Fagerström } \\
\text { score }\end{array}$ & $\begin{array}{l}\text { Mean } C O \\
\text { level }(p p m)\end{array}$ & \\
\hline $\begin{array}{l}\text { Multicomponent } \\
\text { groups } \\
(\mathrm{n}=88)\end{array}$ & 25.95 & 0.72 & 6.85 & 24.11 & 14.23 \\
\hline $\begin{array}{l}\text { American Lung } \\
\text { Association manual } \\
(\mathrm{n}=59)\end{array}$ & 20.23 & 1.88 & 5.07 & 25.21 & 10.13 \\
\hline $\begin{array}{l}\text { LifeSign } \\
\quad(\mathrm{n}=59)\end{array}$ & 26.74 & 2.16 & 5.83 & 27.95 & 17.26 \\
\hline $\begin{array}{l}\text { One-hour clinics } \\
(\mathrm{n}=23)\end{array}$ & 23.55 & 1.62 & 5.73 & 23.30 & 11.04 \\
\hline \multirow{2}{*}{$\begin{array}{l}\text { Brief Individual } \\
\text { Counselling } \\
(\mathrm{n}=33)\end{array}$} & 23.90 & not asked & 6.92 & 21.27 & 12.97 \\
\hline & an $=24.07$ & & & \multicolumn{2}{|c|}{ Mean $=13.13$} \\
\hline
\end{tabular}

One-way ANOVA did not reveal significant differences among the baseline Fagerström scores for any of the groups. However, three other baseline characteristics differed significantly among the groups. First, the number of cigarettes smoked differed, $F(4228)=2.46$, $\mathrm{p}<0.05$. In this analysis one subject was dropped from the Brief Individual Counselling group because of being an outlier (3.35 standard deviations from the mean of the group). Post hoc analyses, using Tukey's method, determined that those participants in the Multicomponent and LifeSign groups smoked significantly more cigarettes than those in the American Lung Association group at baseline.

Second, the number of prior attempts to stop smoking differed among the groups, $F$ $(3197)=4.35, \mathrm{p}<0.01$. The number of prior attempts was not asked of the Brief Individual Counselling group and they were excluded from this analysis. Further, because the variance of the groups was not homogeneous, the reciprocal of this variable was used as a transformation to satisfy this assumption of the ANOVA. Post hoc analyses, again using Tukey's method, determined that those in the Multicomponent group had significantly fewer quit attempts than those in the American Lung Association and LifeSign groups.

Finally, baseline expired CO levels differed among the groups, $F(4253)=2.66, \mathrm{p}<0.05$. Post hoc analyses determined that the LifeSign group had significantly higher $\mathrm{CO}$ levels at baseline than the Brief Individual Counselling group. No other differences were found in $\mathrm{CO}$ levels at baseline.

Analysis revealed no significant differences for age, gender, baseline Fagerström score, baseline number of cigarettes smoked or baseline $\mathrm{CO}$ between the group reached at follow-up and the group not reached.

The participants in all programmes were predominately female $(83 \%)$, which reflected the significantly higher percentage of female employees in the hospital. There were no differences among the groups in the number of cigarettes smoked at the final follow-up. In a repeated measures ANOVA, there was a significant decrease in the number of cigarettes smoked from baseline to the final follow-up, $F$ $(1172)=126.30, \mathrm{p}<0.001$. The baselinefollow-up, repeated smoking measure did not interact with the group variable, indicating that there were no differential effects of the treatments on the number of cigarettes smoked.

At follow-up, the American Lung Association and LifeSign groups were asked if they had used their programmes and whether their goal in participating was to control or reduce smoking rather than to stop smoking. For the American Lung Association group, $21 \%$ indicated that they had not used their programme at all and $21 \%$ indicated that their goal was to control smoking or smoke less. For the LifeSign group, these figures were $13 \%$ and $28 \%$, respectively.

There were no differences among the groups in terms of policy influence on smoking behaviour. However, the influence of the policy in decreasing smoking was positively related to the number of cigarettes smoked at baseline, such that those who reported the policy having more influence on decreasing smoking were heavier smokers at baseline, $r(173)=0.185$, $\mathrm{p}<0.05$.

Two other policy relationships approached significance. First, the influence of the policy was negatively related to the number of cigarettes smoked at the final follow-up, $r$ (170) $=-0.141, \mathrm{p}=0.07$, such that the more influence the policy had in decreasing one's smoking, the fewer cigarettes one smoked. Second, the influence of the policy was positively related to the age of participants, $r(183)=$ $0.136, p=0.07$, such that older participants were more influenced by the policy.

\section{SURVEY}

The total return rate for the initial smoking survey was $69.2 \%(6050 / 8742)$ of which 5190 were usable. Follow-up questionnaires were sent to the 4480 people who completed the initial survey and were still employed at the hospital one year later. The return rate for the follow-up survey was $76.4 \%(3423 / 4480)$ of which $84 \%$ were usable $(n=2877)$ because of incomplete information. Respondents to both surveys reflected the same socioeconomic and occupational distributions.

Survey results are summarised in table 3, which shows the mean number of cigarettes smoked by institution employees and overall 
Table 3 Mean number of cigarettes smoked by occupation and overall smoking prevalence ${ }^{\star}$

\begin{tabular}{|c|c|c|c|c|c|c|}
\hline & \multicolumn{4}{|c|}{ Mean number of cigarettes smoked } & & \\
\hline & \multicolumn{2}{|c|}{6 Months pre-ban } & \multicolumn{2}{|c|}{6 Months post-ban } & \multicolumn{2}{|c|}{$p^{\star \star}$} \\
\hline & per day & at work & per day & at work & day & work \\
\hline $\begin{array}{l}\text { Clerical }(908 / 507)^{\star \star \star} \\
\text { Nurses }(1048 / 554) \\
\text { Physicians }(818 / 517) \\
\text { Service/Tech } \\
\quad \text { Maintenance }(848 / 393)\end{array}$ & $\begin{array}{l}16.3 \\
15.2 \\
15.5 \\
15.3\end{array}$ & $\begin{array}{l}8.4 \\
5.6 \\
8.8 \\
7.2\end{array}$ & $\begin{array}{l}12.3 \\
13.0 \\
11.2 \\
12.9\end{array}$ & $\begin{array}{l}3.4 \\
2.7 \\
4.5 \\
4.3\end{array}$ & $\begin{array}{l}0.0001 \\
0.0001 \\
0.0010 \\
0.0001\end{array}$ & $\begin{array}{l}0.0001 \\
0.0001 \\
0.0059 \\
0.0001\end{array}$ \\
\hline $\begin{array}{l}\text { Supervisors }(469 / 294) \\
\text { Other }(1099 / 612)^{\star \star \star \star}\end{array}$ & $\begin{array}{l}20.5 \\
17.1\end{array}$ & $\begin{array}{r}10.7 \\
7.5\end{array}$ & $\begin{array}{l}16.3 \\
12.7\end{array}$ & $\begin{array}{l}4.3 \\
4.4\end{array}$ & $\begin{array}{l}0.0001 \\
0.0006\end{array}$ & $\begin{array}{l}0.0001 \\
0.0008\end{array}$ \\
\hline Total & 16.4 & 7.8 & 13.1 & 3.8 & 0.0001 & 0.0001 \\
\hline $\begin{array}{l}\text { Prevalence of } \\
\text { current smokers }(\%)\end{array}$ & 21.7 & & 16.2 & & 0.0001 & \\
\hline
\end{tabular}

* Most of the data in this table were published in a similar table in $\mathcal{F} A M A 1990 ; 264$ :

1565-9. "Copyright 1990, American Medical Association."

$\star \star$ Student's paired t-tests comparing mean change from pre-ban to post-ban in specific occupational categories.

pational categories.

$\star \star \star \star$ Other $=$ non-designated occupations, dietitians, social workers, psychologists, healthrelated therapists. time required. Using this method, it was quite clear that the multicomponent group was the most expensive and the one-hour clinics the least. The three self/minimal-help programmes all required about the same amount of staff time, which involved very little time per participant but a significant amount of staff time overall. The two programmes with the highest success rate were the multicomponent group and the one-hour clinics. The three self/minimal-help programmes together had the largest number of participants but very few succeeded in stopping smoking.

Although the different stop-smoking programmes offered here varied greatly in terms of the number of staff hours required and the number of people who succeeded in stopping smoking, each type of programme may serve some purpose when implementing worksite smoking restrictions. For example, the self/ minimal-help groups attracted participants who smoked fewer cigarettes and had made more previous attempts to stop smoking than smokers selecting a formal group programme. These people may have learned some skills to help them reduce their cigarette consumption and may be more likely to stop in the future as a result of this attempt.

These results indicate that different types of smokers may choose different strategies for smoking cessation and suggests that making a variety of smoking cessation strategies available to employees when implementing a more restrictive smoking policy may meet the needs of more employees and result in increased employee participation. We cannot predict how many employees would have sought smoking cessation assistance if fewer programmes had been offered, but it seems plausible to assume that the number of participants would have been lower. Since it has been reported that the number of previous attempts to stop smoking is positively associated with successful quitting in the future ${ }^{28}$, increasing participation in smoking cessation programmes should ultimately result in higher cessation rates. Despite the relatively small percentage of smokers who participated in stop-smoking programmes here, the number of employees joining a multicomponent group smoking cessation programme quadrupled during the 12-month period following announcement of the impending ban compared to several pre-ban years. Participation in the multicomponent group returned to near preban levels one year after the ban, suggesting that the increased attendance six months prior to implementation of the ban was a result of the impending ban. Cost was probably not a major factor since the programme was free six months prior to the ban as well as one year after; the cost to participants was $\$ 55$ in previous years.

The results presented here also showed that the self-reported prevalence of smoking among employees decreased by 5.5 percentage points. Additionally, the total number of cigarettes smoked per day and at work decreased significantly for all reported occupational categories. These data are based on self-report and minimal-help programme. ${ }^{27}$

Although no formal cost analyses were made for the stop-smoking programmes offered here, the relative cost of each programme can be estimated by examining the amount of staff 
may be subject to social desirability bias, ${ }^{29,30}$ but are in agreement with data reported by others. ${ }^{11,15-17}$ No data were collected on the approximately $30 \%$ of employees who did not return the initial survey and this is a limitation of the study. However, it might be predicted that smokers would be less likely to return the survey because of reasons such as not wanting to admit to being a smoker or not wanting to cooperate with anything related to a restrictive smoking policy. Since only 262 employees participated in hospital-sponsored stop-smoking cessation programmes and only 22 of these successfully stopped smoking for a year, the majority of employees who quit and reduced smoking appeared to do so on their own. This is not surprising given that most smokers who try to stop smoking do so without outside support and prefer self-help methods over formal programmes. ${ }^{31}$

We have found only two studies where much larger reductions in smoking prevalence were found following the implementation of a restrictive smoking policy. ${ }^{18,19}$ These studies found that $26 \%$ and $21 \%$ of identified smokers had stopped smoking 20 months following an initial survey. The first of these studies took place in a hospital and the second in a telephone company, so that setting alone cannot account for the differences between these and earlier reports as has been suggested. ${ }^{19}$ The change in smoking prevalence observed at a worksite following the implementation of a more restrictive smoking policy is probably influenced by a number of factors, such as the type of worksite, degree of smoking restriction implemented, previous smoking policy, the timing of the baseline survey with respect to policy implementation, and the extensiveness of the educational and smoking cessation campaigns. The relationships between these variables and changes in employee smoking are unclear at this time.

Overall, the smoking cessation programmes offered here had only modest success in helping employees to stop smoking. The one-year quit rate for all programmes combined was $8.4 \%$, with a quit rate of $12.5 \%$ for the Multicomponent Group. Actual smoking cessation rates may have been greater than reported since anyone not contacted was counted as a smoker and only those reporting continuous 12-month abstinence, verified by CO measurement were counted as successes. The success rate for the Multicomponent Group programme was somewhat lower than expected based on previous results from other similar programmes and from this programme prior to the announcement of the smoking ban. ${ }^{13,23}$ The low success rate observed for the self-help programmes was similar to results reported elsewhere, ${ }^{32}$ except for the higher cessation rates reported previously with LifeSign. ${ }^{33}$ Still, the overall success rate for all the programmes offered here combined was greater than the estimated $3.4 \%$ of smokers who stopped smoking long-term on their own. ${ }^{34}$ Direct comparisons between the various smoking cessation programmes offered here cannot be made because different strategies were used to recruit participants and groups were not identical at baseline.

Participants in all groups were only contacted one year following the implementation of the smoking ban because of the staff time involved in conducting such follow-ups. Success rates immediately following the ban or at other times during the year are not available. The only participants counted as successes were those who reported not smoking for the entire 12-month period following the ban and with confirmatory $\mathrm{CO}$ measurements. It is likely that other participants stopped smoking for a while and then relapsed. The absence of these data is a weakness in the study; such data would be a useful addition in future studies.

Since participation in smoking cessation programmes appears to have been influenced by the smoking ban, it is very likely that some participants were not very self-motivated to stop smoking but were participating mainly in response to the impending smoking ban. Degree of motivation was measured here for only the American Lung Association and LifeSign groups and provides some support for this hypothesis as some participants did not even use their materials. Also, some participants indicated that their goal in participating was to control smoking or to smoke less rather than to stop smoking.

In conclusion, these results are in agreement with other studies in demonstrating that workplace smoking restrictions provide a means by which many smokers will reduce their daily cigarette consumption. Although controlled smoking has not been shown to be a generally sustainable strategy under most conditions, ${ }^{35}$ the implementation of restrictive smoking policies may make long-term controlled smoking more viable in itself, and a useful intermediate step in the process of smoking cessation. Although the number of people in this study who stopped smoking within a year of implementation of the smoking ban seems relatively small, it has been suggested that smoking policies may be most effective in preventing relapse in those who have already stopped smoking, rather than in motivating cessation initially. ${ }^{36}$ Long-term data are needed to answer this question. Smoking restrictions may also have indirect effects on attitudes and norms about the acceptability of smoking. Policies restricting smoking reinforce non-smoking as the norm as well as increase social support for smoking cessation. As the US moves closer to achieving the Healthy People $2000^{37}$ objective of increasing to at least $75 \%$ the proportion of worksites with a formal smoking policy that prohibits or severely restricts smoking at the workplace, smoking prevalence and cigarette consumption among employees working at such worksites should continue to decrease.

The authors wish to thank Jack E Henningfield for his help in preparing this manuscript.

Fielding JE. Banning worksite smoking. Am $\mathcal{f}$ Public Healt $1986 ; 76: 957-9$.

2 Bureau of National Affairs, Inc. SHRM-BNA Survey No 5 , Smoking in the Workplace. Washington, DC, 1991. 
3 Coalition on Smoking OR Health, 1150 Connecticut Avenue NW, Suite 820, Washington, DC 20036, January 1993

4 American College of Health Care Executives: Smoking policy survey return results. Read before the Congress on policy survey return results. Read before the Congress on

5 Stillman FA, Becker DM. The status of restrictive smoking policies: a survey of medical schools in the United States and Canada. Am $\mathcal{F}$ Public Health 1991; 81: 101-2.

6 Rigotti NA. Trends in the adoption of smoking restrictions in public places and worksites. NY State $\mathcal{F}$ Med 1989; 19-26.

7 US Department of Health and Human Services. The health consequences of smoking : cancer and chronic lung disease in the workplace. A report to the Surgeon General, 1985. Rockville, Maryland: Public Health Service, Office on Smoking and Health, 1985. (DHHS Publication No 8550207.)

8 Survey of attitudes toward smoking. Princeton, New Jersey : Gallup Organization, July 1985.

9 Eriksen MP. Smoking policies at Pacific Bell. Corporate Commentary $1985 ; 1(4): 24-34$.

10 Survey of attitudes toward smoking. Princeton, New Jersey: Gallup Organization, April 1987.

11 Biener L, Abrams DB, Follick MJ, Dean L: A comparative evaluation of a restrictive smoking policy in a general hospital. Am f Public Health 1989; 79: 192-5.

12 US Department of Health and Human Services. The health consequences of smoking: nicotine addiction. A report of the Surgeon General, Washington, DC: US Government Printing Office, 1988: 150 (DHHS Publication No (CDC) 88-8406.)

13 Glasgow RE, Lichtenstein E. Long-term effects of behavioral smoking cessation interventions. Behav Ther 1987; 18: 297-324

14 Cohen S, Lichtenstein E, Prochaska JO, Rossi JS, Gritz ER, Carr CR. Debunking myths about self-quitting: evidence from 10 prospective studies of persons who attempt to quit smoking by themselves. Am Psychol 1989; 44: 1355-65.

15 Rosenstock IM, Stergachis A, Heaney C. Evaluation of smoking prohibition policy in a health maintenance organization. Am $\mathcal{F}$ Public Health 1986; 76: 1014-5.

16 Petersen LR, Helgerson SD, Gibbons CM, Calhoun CR, Ciacco KH, Pitchford KC. Employee smoking behavior changes and attitudes following a restrictive policy on worksite smoking in a large company. Public Health Rep 1988; 103: 115-20.

17 Borland R, Chapman S, Owen N, Hill D. Effects of workplace smoking bans on cigarette consumption. $A m \mathcal{F}$ Public Health 1990; 80:178-80.

18 Andrews JL. Reducing smoking in the hospital: an effective model program. Chest 1983;84:206-9.

19 Sorensen G, Rigotti N, Rosen A, Pinney J, Prible R. Effects of a worksite nonsmoking policy: evidence for increased of a worksite nonsmoking policy: evidence for incr
cessation. Am $\mathcal{F}$ Public Health 1991; 81: 202-4.

20 Becker DM, Conner HR, Waranch HR, Swank R, Weida S, Oski F. Banning smoking in a children's hospital: are employees supportive? Prev Med 1989; 18: 72-8.
21 Becker DM, Conner HR, Waranch HR, Stillman F, Pennington L, Lees $P$ et al. End of an era: the impact of a total ban on smoking in The Johns Hopkins Childrens' Centre. $\not A M A 1989 ; 262$ : 799-802

22 Stillman FA, Becker DM, Swank RT, Hantula D, Moses $\mathrm{H}$, Glantz $\mathrm{S}$ et al. Ending smoking at The Johns Hopkins Medical Institutions: an evaluation of smoking prevalence and indoor air pollution. $\mathcal{F} A M A 1990 ; 264$ : $1565-9$.

23 Edmunds ME, Conner H, Jones C, Gorayeb R, Waranch $H R$. Evaluation of a multicomponent group smoking cessation program. Prev Med 1991; 20: 404-13.

24 Frederiksen LW, Martin JE. Carbon monoxide and smoking behavior. Addict Behav 1979; 4: 21-30.

25 Fagerström, K-O. Measuring degree of physical dependence to tobacco smoking with reference to individualization of treatment. Addict Behav 1978; 3: 235-41.

26 US Department of Health and Human Services. National Survey of Worksite Health Promotion Activities. Washington, DC: Office of Disease Prevention and Health Promotion, 1986.

27 Bertera BL, Oehl LK, Telepchak JM. Self-help versus group approaches to smoking cessation in the workplace: eighteen-month follow-up and cost analysis. Am f Health Promotion 1990; 4: 187-92.

28 Mothersill KJ, McDowell I, Rosser W. Subject characteristics and long-term post-program smoking cessation. Addict Behav 1988; 13: 29-36.

29 Glasgow RE. Assessment of smoking behavior in relation to worksite smoking policies. NY State f Med 1989; 31-4.

$30 \mathrm{Kozlowski} \mathrm{LT}$ Heatherton TF. Self-report issus in cigarette smoking: state of the art and future directions. Behav Assess 1990; 12: 53-75.

31 Fiore MC, Novotny TF, Pierce JP, Giovino GA, Hatziandreu EJ, Newcomb PA et al. Methods used to quit andreu EJ, Newcomb PA et al. Methods used to quit smoking in the United States: do

32 Davis AL, Faust R, Ordentlich $M$. Self-help smoking cessation and maintenance programs: a comparative tudy with 12-month follow-up by the American Lun Association. Am F Public Health 1984; 74: 1212-7.

33 Prue DM, Riley AW, Orlandi MA, Jerome A. Developmen of a computer assisted smoking cessation program: preliminary report. $\mathcal{F}$ Advancement Med $1990 ; 131-9$.

34 Hatziandreu EJ, Pierce JP, Lefkopoulou M, Fiore MC, Mills SL, Novotny TE et al. Quitting smoking in the United States in 1986. F Natl Cancer Inst 1990; 82: $1402-6$

35 Hill D, Weiss DJ, Walker DL, Jolly D. Long term evaluation of controlled smoking as a treatment outcome. Br f Addict 1988; 83:203-7.

36 Parker S, Warner K. Smoking in the workplace: research needs and potential applications. NY State $\mathcal{F}$ Med 1989 ; 29-36.

37 Healthy People 2000: National Health Promotion and Disease Prevention Objectives. US Department of Health and Human Services Publication No (PHS) 91-50212, 1991

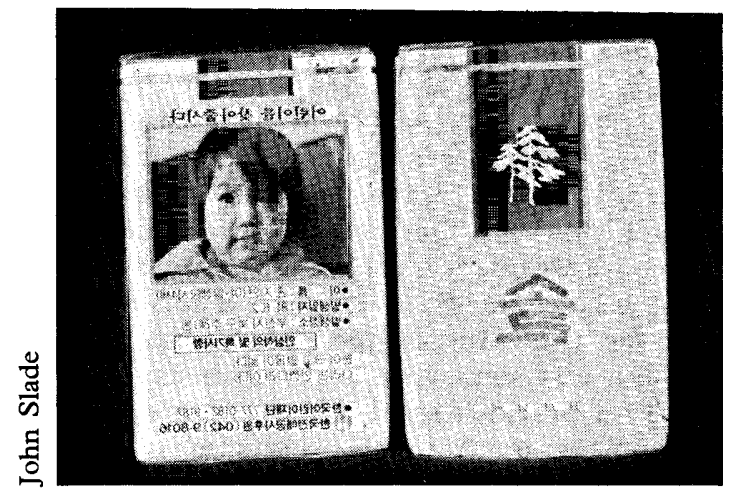

Notice of a missing child on a South Korean cigarette pack 